\title{
Innovative computational approaches shed light on genetic mechanisms underlying cognitive impairment among children born extremely preterm
}

\author{
Weifang Liu ${ }^{1}$ (1), Quan Sun ${ }^{1}$, Le Huang ${ }^{2}$, Arjun Bhattacharya ${ }^{3}$, Geoffery W. Wang ${ }^{1}$, Xianming Tan ${ }^{1,4}$, \\ Karl C. K. Kuban ${ }^{5}$, Robert M. Joseph ${ }^{6}$, T. Michael O'Shea ${ }^{7}$, Rebecca C. Fry ${ }^{8 \dagger}$, Yun Li ${ }^{1,9,10^{*}+}$ and \\ Hudson P. Santos Jr $r^{11^{*+}}$
}

\begin{abstract}
Background: Although survival rates for infants born extremely preterm (gestation $<28$ weeks) have improved significantly in recent decades, neurodevelopmental impairment remains a major concern. Children born extremely preterm remain at high risk for cognitive impairment from early childhood to adulthood. However, there is limited evidence on genetic factors associated with cognitive impairment in this population.

Methods: First, we used a latent profile analysis (LPA) approach to characterize neurocognitive function at age 10 for children born extremely preterm. Children were classified into two groups: (1) no or low cognitive impairment, and (2) moderate-to-severe cognitive impairment. Second, we performed TOPMed-based genotype imputation on samples with genotype array data $(n=528)$. Third, we then conducted a genome-wide association study (GWAS) for LPA-inferred cognitive impairment. Finally, computational analysis was conducted to explore potential mechanisms underlying the variant $x$ LPA association.

Results: We identified two loci reaching genome-wide significance ( $p$ value $<5 \mathrm{e}-8$ ): TEA domain transcription factor 4 (TEAD4 at rs 11829294, $p$ value $=2.40$ - 8 ) and syntaxin 18 (STX18 at rs79453226, $p$ value $=1.91$ e- 8 ). Integrative analysis with brain expression quantitative trait loci (eQTL), chromatin conformation, and epigenomic annotations suggests tetraspanin 9 (TSPAN9) and protein arginine methyltransferase 8 (PRMT8) as potential functional genes underlying the GWAS signal at the TEAD4 locus.
\end{abstract}

Conclusions: We conducted a novel computational analysis by utilizing an LPA-inferred phenotype with genetics data for the first time. This study suggests that rs 11829294 and its LD buddies have potential regulatory roles on genes that could impact neurocognitive impairment for extreme preterm born children.

\footnotetext{
*Correspondence: yunli@med.unc.edu; hsantosj@email.unc.edu

${ }^{\dagger}$ Rebecca C. Fry, Yun Li, and Hudson P. Santos are co-senior authors.

${ }^{1}$ Department of Biostatistics, University of North Carolina at Chapel Hill,

Chapel Hill, NC, USA

${ }^{11}$ School of Nursing, University of North Carolina at Chapel Hill, Chapel

Hill, NC, USA

Full list of author information is available at the end of the article
}

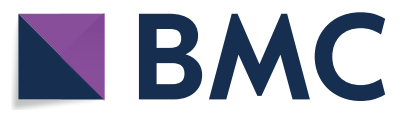

(c) The Author(s) 2022. Open Access This article is licensed under a Creative Commons Attribution 4.0 International License, which permits use, sharing, adaptation, distribution and reproduction in any medium or format, as long as you give appropriate credit to the original author(s) and the source, provide a link to the Creative Commons licence, and indicate if changes were made. The images or other third party material in this article are included in the article's Creative Commons licence, unless indicated otherwise in a credit line to the material. If material is not included in the article's Creative Commons licence and your intended use is not permitted by statutory regulation or exceeds the permitted use, you will need to obtain permission directly from the copyright holder. To view a copy of this licence, visit http://creativecommons.org/licenses/by/4.0/. The Creative Commons Public Domain Dedication waiver (http://creativeco mmons.org/publicdomain/zero/1.0/) applies to the data made available in this article, unless otherwise stated in a credit line to the data. 
Keywords: Cognitive impairment, Neurodevelopment, Preterm children, Genome-wide association study (GWAS), Latent profile analysis (LPA), Genetic mechanisms

\section{Background}

Extreme prematurity (birth $<28$ weeks of gestation) remains one of the leading causes of neonatal morbidity and mortality in the USA [1]. Although survival rates for infants born extremely preterm have improved dramatically in recent decades, children born extremely preterm remain at higher risk for cognitive impairment, with lower average general intelligence and executive function deficit [2-6] and 9-fold higher risk of severe cognitive impairment compared to children born full-term [7-13]. Adverse neurodevelopmental outcomes, such as cognitive impairment, affect $\sim 1$ million preterm infants born each year [14] and may persist through adulthood [1518]. Although cognitive impairment is not always severe, even mild deficits can have substantial impact, resulting in a spectrum of outcomes from difficulties in school to inability to lead an independent adult life [19]. Specific problems can include deficits in executive function, language, learning and memory, attention, perceptual-motor function, and social cognition $[3,6,20,21]$, which negatively affect well-being [19]. Cognitive impairment has life-long effects on quality of life, with significant familial and social capital costs. Although precise data are limited [22], lifetime costs collectively for children born in 2000 with intellectual disability alone are estimated at $\$ 51.2$ billion [23].

Despite substantial research efforts to understand neurodevelopment outcomes, we know remarkably little about genetic factors and molecular mechanisms influencing cognitive function in preterm children. Previous genetic studies have discovered hundreds of genetic variants that can predispose children to neurodevelopmental disorders including autism spectrum disorder [24], attention deficit disorder with hyperactivity [25], intellectual disability [26, 27], specific language impairment [28], specific learning disorders [29], and childhood onset schizophrenia [30]. Some genetic studies have evaluated genetic risk factors for neurodevelopmental outcomes for preterm children or children with low birth weight [31-36]. MAOA was found to be associated with mental development throughout early childhood among preterm children [31]. A variant rs4074134 of $B D N F$, and a rare insertion/deletion in the intron region of SLC6A4 were significant predictors of cognitive performance at school age in a study of genetic risk factors for poor cognitive development in children with low birth weight [36]. With preterm infants from a randomized controlled trial (RCT) examining antenatal exposure to corticosteroids,
Clark et al. found variants of $I L 1 B, I L 4 R$, and IL6 associated with lower scores on the Bayley's Scales of Infant Development and developmental delay at age 2 [34], and Costantine et al. [33] found that variants of VIP and GRIN3A were associated with cerebral palsy. A COMT variant was associated with reduced corpus callosum size in adults with history of preterm birth [32].

However, previous studies do not explain the pathways through which these variants or genes might influence the risk of poor cognitive outcomes, and few genomewide association studies (GWAS) examined the genomic regions associated with cognitive function among children born extremely preterm. Therefore, identifying genetic factors that are associated with children's cognitive function and understanding related mechanisms are necessary to develop earlier screening assessments and effective precision interventions and understand why some preterm children of the same gestational age do worse than others. To advance along these directions, we utilized samples from the extremely low gestational age newborns (ELGAN) cohort [37], the largest US-based study of children born extremely preterm, to identify genetic factors associated with cognitive impairment at age 10 years. Finally, integrative analysis with brain expression quantitative trait loci (eQTL) and chromatin interactome data was performed to identify potential causal variants and functional genes underlying the GWAS associations.

\section{Methods}

\section{Study participants}

ELGAN is a multicenter cohort study originally designed to identify exposures increasing risk of structural and functional neurologic disorders in children born extremely preterm [37]. A total of 1506 infants born before the 28th week of gestation and 1249 mothers were enrolled during the years 2002-2004. Study participants were enrolled at 14 hospitals in the United States to achieve a large enough sample size and generalizability. The enrollment and consent procedures were approved by the individual institutional review boards. At the age of 10 years, 889 of the surviving children returned for follow up (ELGAN2, 92\% of the 966 who were recruited for this phase of the ELGAN Study) and were assessed for cognition capacity, learning abilities, and impairments in executive function [7]. Of these children, 528 had genotype data available for analysis and thus constitute the sample size of this paper. Table 1 summarizes 
Table 1 Participant characteristics of the ELGAN2 subset and ELGAN2 cohort

\begin{tabular}{|c|c|c|}
\hline Variable name & $\begin{array}{l}\text { ELGAN2 subset ( } N \\
=528) \\
n(\% \text { or SD) }\end{array}$ & $\begin{array}{l}\text { ELGAN2 }(N=889) \\
n(\% \text { or } S D)\end{array}$ \\
\hline \multicolumn{3}{|l|}{ Infant sex } \\
\hline Male & 274 (51.9\%) & 455 (51.2\%) \\
\hline Female & 254 (48.1\%) & 434 (48.8\%) \\
\hline \multicolumn{3}{|l|}{ Cognitive impairment } \\
\hline No/Low & 390 (73.9\%) & $660(74.2 \%)$ \\
\hline Moderate/Severe & 138 (26.1\%) & $214(24.1 \%)$ \\
\hline Not reported & 0 & $15(1.7 \%)$ \\
\hline Gestational age & $26.1(1.27)$ & $26.1(1.28)$ \\
\hline \multicolumn{3}{|l|}{ Maternal education } \\
\hline$\leq 12$ years & 205 (38.8\%) & 355 (39.9\%) \\
\hline $13-15$ years & $119(22.5 \%)$ & $202(22.7 \%)$ \\
\hline $16+$ years & $204(38.6 \%)$ & $306(34.4 \%)$ \\
\hline Not reported & 0 & $26(2.9 \%)$ \\
\hline \multicolumn{3}{|l|}{ Maternal smoking } \\
\hline Yes & $128(24.2 \%)$ & $215(24.2 \%)$ \\
\hline No & 400 (75.8\%) & $655(73.7 \%)$ \\
\hline Not reported & 0 & $19(2.1 \%)$ \\
\hline \multicolumn{3}{|l|}{ Race } \\
\hline White & 342 (64.8\%) & $554(62.3 \%)$ \\
\hline Black & 133 (25.2\%) & $227(25.5 \%)$ \\
\hline Other & $53(10.0 \%)$ & $98(11.0 \%)$ \\
\hline Not reported & 0 & $10(1.1 \%)$ \\
\hline \multicolumn{3}{|l|}{ Public insurance } \\
\hline Yes & $167(31.6 \%)$ & $307(34.5 \%)$ \\
\hline No & $361(68.4 \%)$ & $568(63.9 \%)$ \\
\hline Not reported & 0 & $14(1.6 \%)$ \\
\hline \multicolumn{3}{|l|}{ Multiple births } \\
\hline Yes & 189 (35.8\%) & $313(35.2 \%)$ \\
\hline No & 339 (64.2\%) & $576(64.8 \%)$ \\
\hline
\end{tabular}

demographic information for the ELGAN2 cohort and the ELGAN2 subset with genetic data $(n=528)$ we used in our analysis.

\section{Cognitive function at age 10 years}

Cognitive function at age 10 years was assessed with latent profile analysis (LPA) [38], which empirically identifies subgroups of children who share similar profiles on a set of measures. The LPA included 9 cognitive measures including verbal and nonverbal intelligence quotient (IQ) and several measures of executive function (EF). IQ was assessed with the School-Age Differential Ability ScalesII (DAS-II) Verbal and Nonverbal Reasoning scales. EF was assessed with two subtests from the DAS-II and five subtests from the Developmental NEuroPSYchological
Assessment-II (NEPSY-II). Working memory was evaluated with the DAS-II Recall of Digits Backwards and Recall Sequential Order test. The NEPSY-II Auditory Attention and Auditory Response Set, Animal Sorting Inhibition, and Inhibition Switching subtests were utilized to examine auditory attention and set switching, concept generation and mental flexibility, and simple inhibition and inhibition shifting, respectively [7]. It has been shown that characterizing cognitive function using measures of executive function in addition to IQ better discriminates the academic performance and educational needs of children born extremely preterm [38]. LPA classifies subjects who share a similar pattern of scores on the measured variables, while maximizing the difference in scoring patterns across distinct profiles [39]. It assigns subjects into a finite number of profiles by identifying the most likely model that describes the heterogeneity of data, which is known as finite mixture models.

To determine the optimal number of profiles, LPA was fit to the data, and Bayesian information criteria (BIC) [40], sample-size-adjusted Bayesian information criteria (SSABIC) [41], and Lo-Mendell-Rubin-adjusted (LMR) likelihood ratio test [42] were used to assess model fit. Children were categorized by their most likely latent profile for further analysis. In this sample, a four-profile model provided the best fit for the data [38]. For our analysis, we used a binary classification that grouped participants into two previously validated distinct profile groups (LPAx) [38, 43]: no or low cognitive impairment and moderate-to-severe cognitive impairment.

\section{Genotype data}

Genomic DNA was isolated from umbilical cords and genotyping was performed using Illumina 1 Million Quad (Illumina Inc, San Diego, California). This work was done as part of the candidate gene analysis of severe intraventricular hemorrhage (IVH) in preterm born infants [44], where infants with birth weights 500-1250 g and severe grades IVH and neonates with normal cranial ultrasounds were enrolled prospectively at 24 universities. A subset of ELGAN participants were provided as additional samples along with samples from a few other studies in the IVH study [44].

We performed variant level and sample level quality control (QC) on genotype data. For variant level QC, we excluded variants with call rate $<90 \%$ or minor allele frequency (MAF) $<1 \%$. For sample level QC, we excluded samples with missing rate $>10 \%$. These resulted in 700,845 SNPs and 528 samples using plink v.1.90 [45, 46].

\section{Genotype imputation}

Starting with the quality controlled (QCed) genotype data, we used the Michigan imputation server [47] for 
phasing and imputation using TOPMed freeze 5 [48] as the reference panel. Specifically, Eagle [49] was used for phasing and Minimac4 [50, 51] was used for imputation. We performed strand matching by dropping ambiguous (i.e., A/T or C/G) SNPs and by flipping nonambiguous SNPs that were initially in - strand when compared to alleles in the + strand observed in the TOPMed freeze 5 reference panel. Genotype data was lifted over to genome build hg38. In total, we obtained $\sim 34$ million well imputed variants, with 5.5 million variants having $\mathrm{MAF}>5 \%, 10.5$ million variants having $\mathrm{MAF}>1 \%$, and 17.4 million variants having MAF $>0.5 \%$. Well imputed variants were defined by having Rsq $>0.8$, where Rsq is the estimated imputation quality metric $[50,51]$. To evaluate the imputation accuracy, we randomly selected $5 \%$ of the genotyped variants on chromosome 1 and performed genotype imputation with the rest $95 \%$ genotyped variants, again with the TOPMed freeze 5 reference panel. The 5\% masked genotyped variants were saved for imputation quality evaluation. Specifically, we calculated the squared Pearson correlation between imputed genotypes and true observed genotypes. For the 1956 variants on chromosome 1 tested, the mean squared Pearson correlation was 0.97 , which suggests that most variants were well imputed even with a relatively small sample size (Fig. S1, Additional file 1), consistent with what has been reported in the literature [52-54].

\section{Genome-wide association analysis}

We used EPACTS 3.3.0 [55] for single variant association testing. To account for relatedness among samples, we used the EMMAX (Efficient Mixed Model Association eXpedited) test [56], which is an efficient implementation of mixed model association accounting for sample structure including population structure and hidden relatedness. Biallelic SNPs with MAF $>2 \%$ (did not account for relatedness) and Rsq $>0.8$ were included in the analysis. In total, 8,535,130 variants were included in the association analysis. For the 528 samples who had genotype and covariates data available, we inferred kinship matrix using EPACTS and top 10 principal components (PCs) from the genotype data using PLINK. We performed the association test on the outcome LPAx, a binary outcome that classifies children into no or low cognitive impairment and moderate-severe cognitive impairment groups. The covariates for the single variant association analysis included gestational age, maternal education, maternal race, sex of the infant, and top 10 PCs. We performed sensitivity analysis for variants showing suggestive signals by further adjusting interaction terms between covariates.

\section{Results}

Association analysis results

We conducted a GWAS on LPAx of 528 samples from the ELGAN2 cohort. We identified two genome-wide significant loci from the 8,535,130 variants tested: STX18 and TEAD4, which are located on chromosome 4 and chromosome 12, respectively (Fig. 1). The index SNPs are rs79453226 $(\mathrm{MAF}=0.036)$ and $\mathrm{rs} 11829294(\mathrm{MAF}$ $=0.145)$ at the STX18 and TEAD4 loci, respectively. The genomic inflation factor $\lambda$, which measures the inflation in the test statistics and is calculated as the ratio of the median of the empirically observed distribution of the test statistics to the expected median (median of a chisquare distribution with one degree of freedom), is 1.038, which suggests no significant inflation of test statistics or excess false positive rate (Fig. 2). Table 2 shows genomewide significant variants, and suggestive variants with $p$ values less than 1e-6. For this set of suggestive variants, we performed additional association analysis by including interaction terms between non-genetic covariates (gestational age, maternal education, maternal race, and sex of the infant). We evaluated each interaction term separately, and we found that the two genome-wide significant loci remained significant and most suggestive loci had similar significance levels as in the original model (Fig. S2, Additional file 1), indicating that our top loci are robust to the further adjustment of interactions between covariates.

Figure 3 shows LocusZoom [59] plots for the two genome-wide significant loci, with linkage disequilibrium (LD) from TOP-LD [60], calculated using TOPMed European and African participants. We can see that in the European population, the lead variant rs11829294 in the TEAD4 region has a number of LD tags (e.g., 21 variants with $r^{2} \geq 0.8$ ) and some of them had highly significant $p$ values; by contrast, the lead variant rs79453226 in the STX18 region has fewer LD tags (2 variants with $r^{2} \geq 0.8$ ) that showed suggestive association (Fig. 3a). In the African population, the lead variant rs11829294 in the TEAD4 region has only $2 \mathrm{LD}$ tags, which did not have significant or suggestive association, and the lead variant rs79453226 in the STX18 region has no LD tag with $r^{2} \geq$ 0.8 (Fig. 3b).

\section{Epigenetic functional annotations}

To further investigate the two loci identified for potential mechanisms, we examined several functional annotation metrics, including the CADD phred score [61] and the fathmm MKL score [62]. CADD phred score measures the deleteriousness of variants and is computed as $-10 * \log 10$ (rank/total). A CADD phred score of $\geq 10$ indicates that the variant is predicted to be among the $10 \%$ most deleterious variants in the human genome, a score 


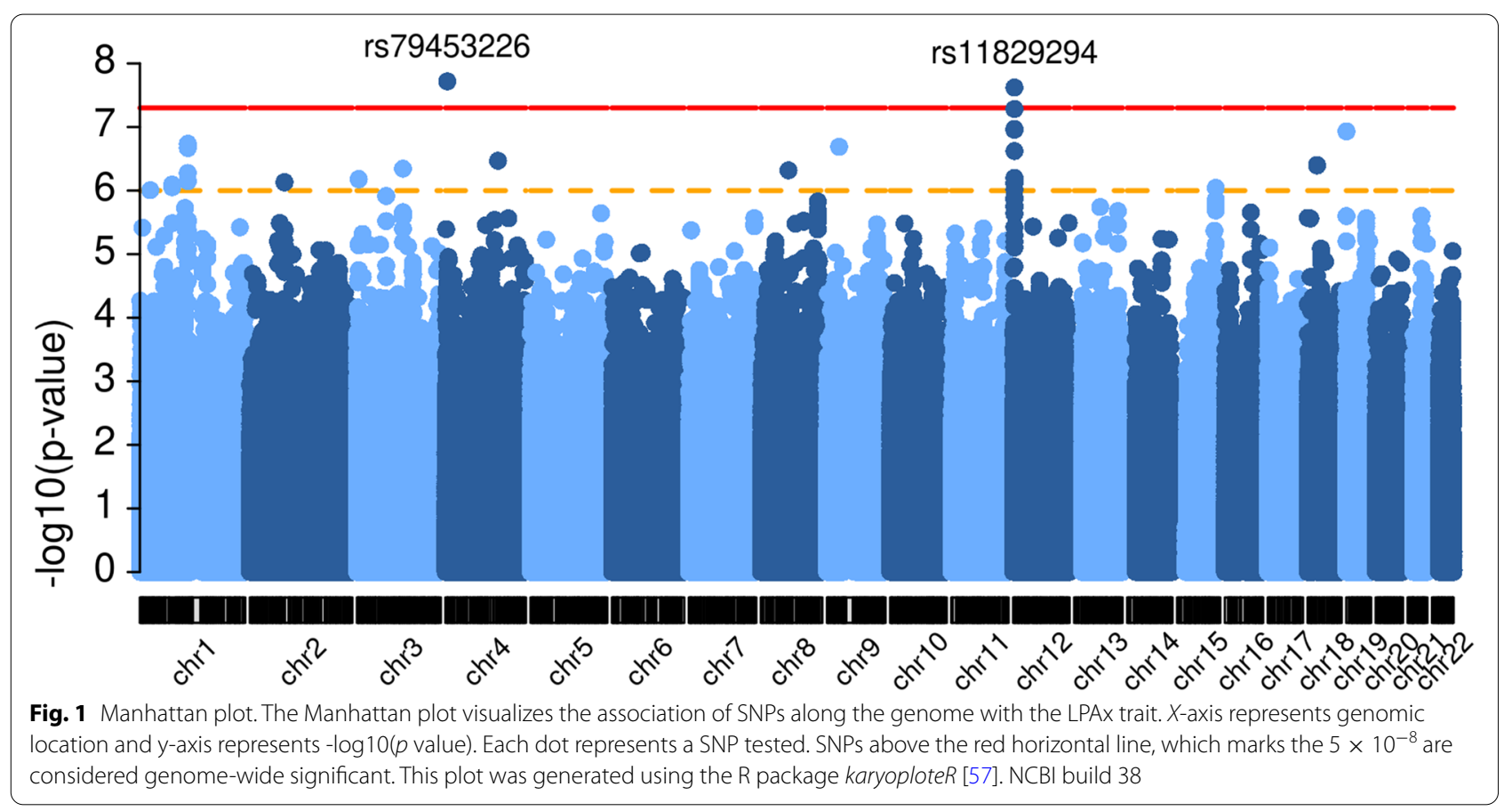

of $\geq 20$ indicates among the $1 \%$ most deleterious. The fathmm MKL score predicts the functional consequences of variants where values above 0.5 are generally considered deleterious, and values below 0.5 neutral or benign. We also looked at the Genehancer feature [63] and the genes predicted by Genehancer. Table 3 shows functional annotations for variants that passed the suggestive $p$ value threshold ( $p$ value $<1 \mathrm{e}-6$ ). We observed that variants rs9424366, rs79946490, rs58545250, and rs17031018 were among the top $10 \%$ most deleterious in the human genome, and variant rs16913588 was predicted to be deleterious (with a fathmm MKL score of 0.97). Several variants were assigned by Genehancer as falling into enhancer regions with target genesTSPAN9, ITPR1, and CLIC4. These results provide evidence that some of the variants might have deleterious effects that are relevant to neurocognitive development in preterm children and suggest additional genes that might be functionally related.

\section{Chromatin interactions}

We examined chromatin conformation data for additional functional implications based on physical contacts from $\mathrm{Hi}-\mathrm{C}$ and alike technologies. Figure 4 shows virtual 4C plots generated by HUGIn2 [64] for the top two loci in adult cortex and fetal cortex Hi-C data [65]. HUGIn2 is a web-based viewer of genome-wide chromatin conformation data to explore chromatin spatial organization across multiple human cell lines and primary tissues. HUGIn2 can additionally incorporate data from multiple sources including genetic variants, chromatin organization features (e.g., topologically associating domains (TADs) [66], frequently interacting regions (FIREs) [67]), gene expression, and epigenetic annotations. For our purpose, we examined $\pm 500 \mathrm{~kb}$ regions around each locus. Significant chromatin interactions between the putative regulatory regions (harboring some GWAS variant(s)) and promoters of genes suggest the likely causal or effector genes regulated by the GWAS variant(s). The results were consistent between adult cortex and fetal cortex. The variant rs79453226 at the STX18 locus was linked to the promoter regions of several genes, including STX18 and NSG1 (Fig. 4a), and the variant rs12322215 at the TEAD4 locus was linked to FKBP4, FOXM1, RHNO1, TULP3, TSPAN9, and PRMT8 (Fig. 4b).

\section{Overlapping with brain eQTL}

Next, we investigated whether we could find any brain eQTL signals among the top variants. We examined all variants with $\mathrm{LD} r^{2} \geq 0.6$ with variants that passed the suggestive $p$ value threshold ( $p$ value $<1 \mathrm{e}-6$ ) using LD calculated from TOPMed European ancestry samples. Table 4 shows variants overlapped with commonMind eQTL [68] with FDR <5\%. Multiple brain eQTLs for PRMT8 on chromosome 12 in LD with the index SNP rs11829294 were identified. 


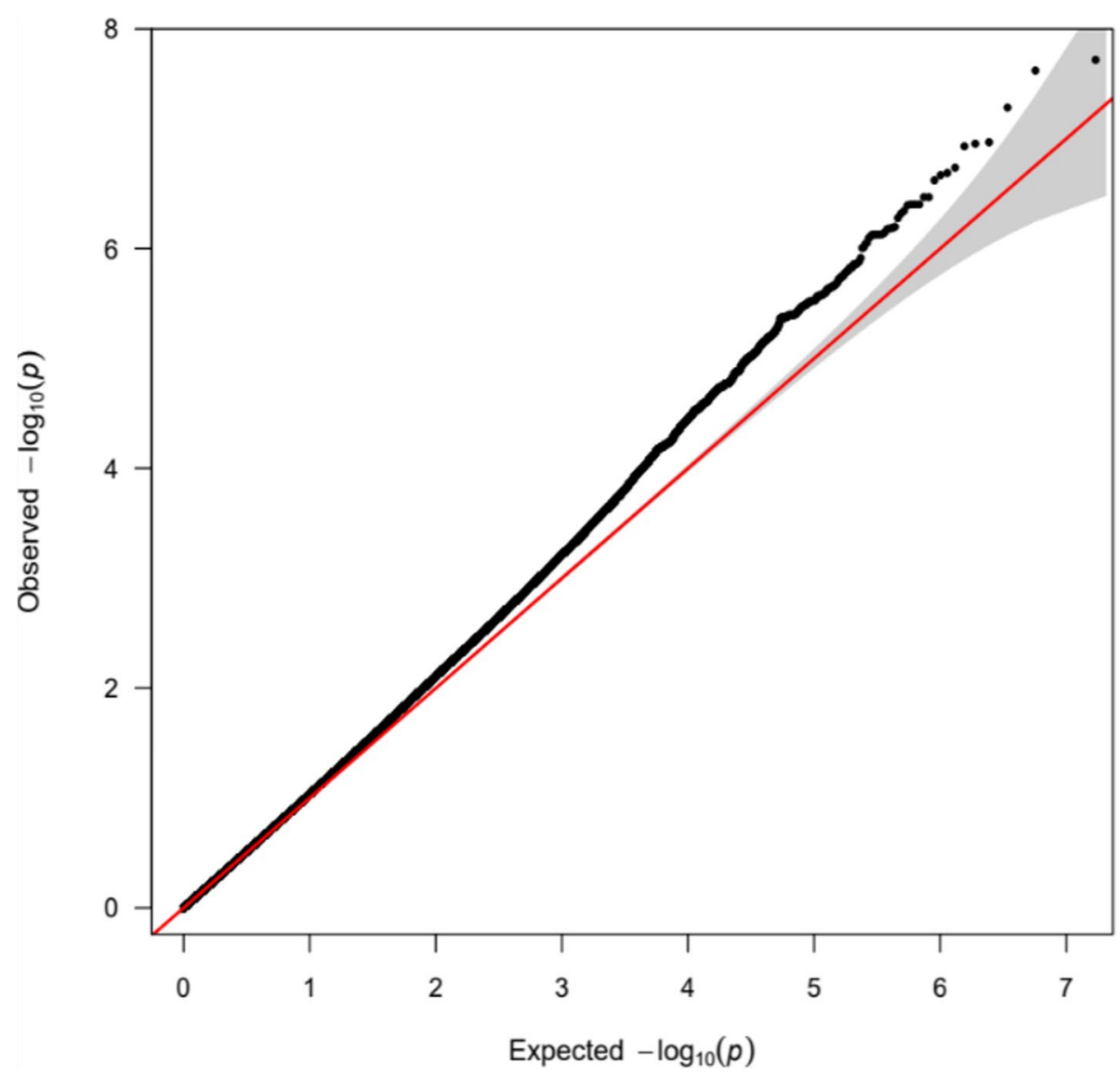

Fig. 2 QQ plot. A quantile-quantile (Q-Q) plot is used to characterize the extent to which the observed distribution of the test statistics follows the expected null distribution. This plot was generated using the R package qaman [58]

\section{Overlapping with selective sweeps}

We also examined whether the identified top variants overlapped with selective sweeps detected by S/HIC [69]. Table 5 shows multiple variants in $\mathrm{LD}\left(r^{2} \geq 0.6\right)$ with the top variants overlapped with selective sweeps: all except one on chromosome 12 at the TEAD4 locus and one in an intergenic locus on chromosome 2 . We found that some variants at the TEAD4 locus were located in soft sweep regions, where selection on standing variation produced qualitatively different skews in LD and allele frequencies.

\section{Discussion}

Cognitive impairment is highly prevalent among children born extremely preterm. Yet, limited evidence is available on the genetic factors that may contribute to this kind of impairment. In this study, we aimed to identify genetic factors that are associated with children's cognitive function and understand related genetic mechanisms by utilizing samples from the ELGAN cohort. Leveraging an LPA-derived phenotype and genetics data, we identified two genome-wide significant loci in our genome-wide association analysis for LPAx (a data-derived cognitive impairment outcome): TEAD4 (rs11829294, $p$ value $=$ $2.40 \mathrm{e}-8)$ and $S T X 18$ (rs79453226, $p$ value $=1.91 \mathrm{e}-8)$.

We utilized chromatin conformation data from multiple human cell lines and primary tissues to see whether there are significant chromatin interactions between the two genome-wide significant loci and their neighboring regions. In adult cortex and fetal cortex, we found that variant rs12322215 ( $p$ value $=1.08 \mathrm{e}-07)$ in high $\mathrm{LD}$ with rs11829294 $\left(r^{2}=0.883\right)$ is linked to promoter regions of a few genes including TSPAN9 and PRMT8 (Fig. 4). Furthermore, the association at the TEAD4 locus rs11829294 and a few other variants that showed suggestive significance at the same locus were assigned by Genehancer as falling into the enhancer region of TSPAN9 (Table 3). We also observed TSPAN9 is highly expressed in both adult cortex and fetal cortex but not in hippocampus, and we did not observe similar chromatin interactions in hippocampus (Fig. 4). TSPAN9 is located at chr12:3,077,355$3,286,564$ (GRCh38/hg38) and is one of tetraspanins, a 
Table 2 Significant and suggestive association results for LPAx

\begin{tabular}{|c|c|c|c|c|c|c|c|c|}
\hline rsID & $\mathrm{Chr}^{\mathrm{a}}$ & Position $^{a}$ & REF & ALT & $P$ value & MAF & Locus & Effect size (s.e.) \\
\hline rs79453226 & chr4 & 4483114 & G & C & $1.91 \mathrm{e}-08$ & 0.036 & STX18 (intron) & $0.421(0.074)$ \\
\hline rs11829294 & chr12 & 3014153 & C & $\mathrm{T}$ & $2.40 \mathrm{e}-08$ & 0.145 & TEAD4 (intron) & $-0.231(0.041)$ \\
\hline rs10774094 & chr12 & 3014630 & $C$ & A & $5.21 \mathrm{e}-08$ & 0.160 & TEAD4 (intron) & $-0.214(0.039)$ \\
\hline rs12322215 & chr12 & 3001421 & G & T & $1.08 \mathrm{e}-07$ & 0.142 & TEAD4 (intron) & $-0.215(0.040)$ \\
\hline rs10128796 & chr12 & 3003552 & G & A & $1.11 \mathrm{e}-07$ & 0.142 & TEAD4 (intron) & $-0.214(0.040)$ \\
\hline rs73916918 & chr19 & 376264 & $C$ & T & $1.17 \mathrm{e}-07$ & 0.020 & THEG (5' UTR) & $0.522(0.097)$ \\
\hline rs59359613 & chr1 & 113154555 & C & T & $1.83 e-07$ & 0.023 & intergenic & $0.465(0.088)$ \\
\hline rs16913588 & chr9 & 28733517 & $\mathrm{~T}$ & C & $2.05 e-07$ & 0.036 & intergenic & $0.396(0.075)$ \\
\hline rs58545250 & chr1 & 113172866 & $\mathrm{~T}$ & C & $2.14 \mathrm{e}-07$ & 0.024 & RP11-389022.4 (downstream) & $0.438(0.083)$ \\
\hline rs61114884 & chr12 & 3004684 & $\mathrm{~T}$ & A & $2.39 \mathrm{e}-07$ & 0.135 & TEAD4 (intron) & $-0.210(0.040)$ \\
\hline rs28411755 & chr4 & 124309484 & $\mathrm{~T}$ & C & $3.40 \mathrm{e}-07$ & 0.025 & intergenic & $0.431(0.083)$ \\
\hline rs7657348 & chr4 & 124310584 & A & G & $3.40 \mathrm{e}-07$ & 0.025 & intergenic & $0.431(0.083)$ \\
\hline rs76946462 & chr18 & 22326760 & A & G & $3.96 \mathrm{e}-07$ & 0.057 & intergenic & $0.278(0.054)$ \\
\hline rs77039990 & chr18 & 22327483 & G & A & $3.97 e-07$ & 0.057 & intergenic & $0.278(0.054)$ \\
\hline rs76500624 & chr18 & 22326662 & G & A & $3.97 \mathrm{e}-07$ & 0.057 & intergenic & $0.278(0.054)$ \\
\hline rs75050632 & chr18 & 22327123 & G & A & $4.03 e-07$ & 0.057 & intergenic & $0.277(0.054)$ \\
\hline rs115606157 & chr3 & 108839197 & $\mathrm{~T}$ & G & $4.53 e-07$ & 0.030 & TRAT1 (intron) & $0.385(0.07)$ \\
\hline rs73690518 & chr8 & 65242418 & $C$ & $\mathrm{~T}$ & 4.80e-07 & 0.048 & intergenic & $0.355(0.070)$ \\
\hline rs17031018 & chr1 & 113100296 & A & G & $5.27 e-07$ & 0.035 & LRIG2 (intron) & $0.377(0.074)$ \\
\hline rs61917974 & chr12 & 3011978 & $\mathrm{~T}$ & C & $6.33 e-07$ & 0.109 & TEAD4 (intron) & $-0.223(0.044)$ \\
\hline rs12296242 & chr12 & 3006641 & G & C & $6.49 \mathrm{e}-07$ & 0.133 & TEAD4 (intron) & $-0.202(0.040)$ \\
\hline rs143601180 & chr3 & 4370781 & A & G & $6.56 \mathrm{e}-07$ & 0.032 & SUMF1 (intron) & $0.383(0.076)$ \\
\hline rs79946490 & chr3 & 4385952 & C & $\mathrm{T}$ & $6.64 \mathrm{e}-07$ & 0.032 & SUMF1 (intron) & $0.383(0.076)$ \\
\hline rs17031120 & chr1 & 113144809 & $\mathrm{~T}$ & C & $7.12 \mathrm{e}-07$ & 0.021 & intergenic & $0.462(0.092)$ \\
\hline rs2163633 & chr2 & 81884390 & C & A & $7.36 \mathrm{e}-07$ & 0.046 & intergenic & $-0.350(0.070)$ \\
\hline rs6716465 & chr2 & 81871292 & G & C & $7.43 e-07$ & 0.045 & intergenic & $-0.350(0.070)$ \\
\hline rs11062457 & chr12 & 3010236 & C & $\mathrm{T}$ & $7.44 \mathrm{e}-07$ & 0.145 & TEAD4 (intron) & $-0.201(0.040)$ \\
\hline rs72921448 & chr2 & 81824332 & $\mathrm{~T}$ & C & $7.44 \mathrm{e}-07$ & 0.045 & intergenic & $-0.350(0.070)$ \\
\hline rs2286647 & chr12 & 3010912 & C & $\mathrm{T}$ & $7.46 \mathrm{e}-07$ & 0.145 & TEAD4 (intron) & $-0.201(0.040)$ \\
\hline rs116629423 & chr2 & 81858789 & A & G & 7.47e-07 & 0.045 & intergenic & $-0.350(0.070)$ \\
\hline rs143923810 & chr12 & 2988024 & C & $\mathrm{T}$ & $7.73 e-07$ & 0.139 & TEAD4 (intron) & $-0.194(0.039)$ \\
\hline rs10493588 & chr1 & 76227682 & C & $\mathrm{T}$ & $8.04 \mathrm{e}-07$ & 0.057 & ST6GALNAC3 (intron) & $0.279(0.056)$ \\
\hline rs17098434 & chr1 & 76232427 & G & A & $8.85 e-07$ & 0.057 & ST6GALNAC3 (intron) & $0.277(0.056)$ \\
\hline rs8025099 & chr15 & 91488748 & C & A & $9.06 \mathrm{e}-07$ & 0.486 & CRAT37 (intron) & $-0.129(0.026)$ \\
\hline rs12318430 & chr12 & 3006040 & C & A & $9.75 e-07$ & 0.132 & TEAD4 (intron) & $-0.201(0.040)$ \\
\hline rs9424366 & chr1 & 24475103 & G & C & $9.86 e-07$ & 0.036 & NIPAL3 (downstream) & $0.349(0.070)$ \\
\hline
\end{tabular}

Ordered by significance

a NCBI build 38

superfamily of glycoproteins that function as "organizers" of cell membranes by recruiting other receptors and signaling proteins into tetraspanin-enriched microdomains and induce normal platelet activation [70]. Those proteins mediate signal transduction events that play a role in the regulation of cell development, activation, growth, and motility. TSPAN9 is highly expressed in normal brain tissues, including cerebellum and cerebellar hemisphere [71]. These pieces of evidence suggest the potential regulatory role of rs11829294 and its LD buddies on the
TSPAN9 gene that could impact cognitive development among children born extremely preterm.

We also performed integrative analysis with brain eQTL to identify potential functional genes underlying the genome-wide significant association. A few brain eQTL for PRMT8 were found to be in high LD with rs11829294 (Table 4). PRMT8 is a member of the protein arginine $N$-methyltransferase (PRMT) family, which mediates protein arginine methylation, a common post-translational modification that has 
a

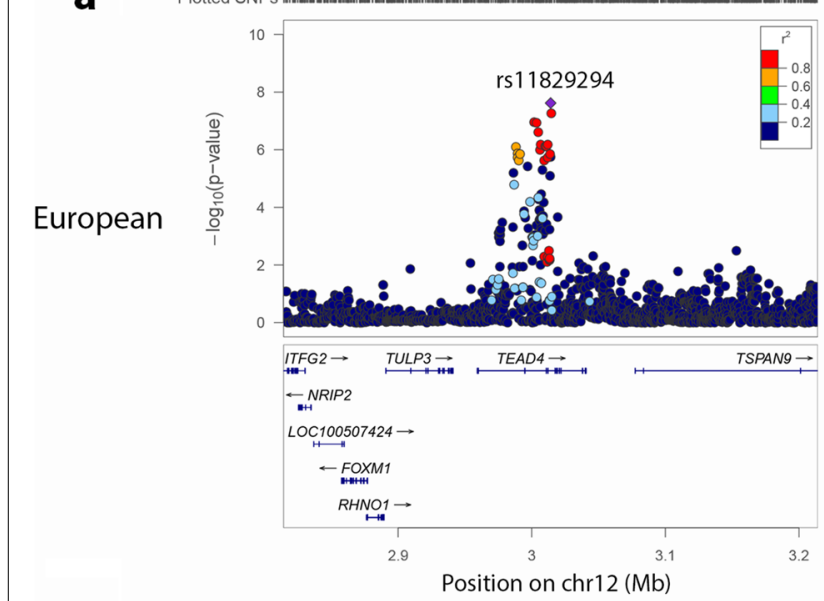

b

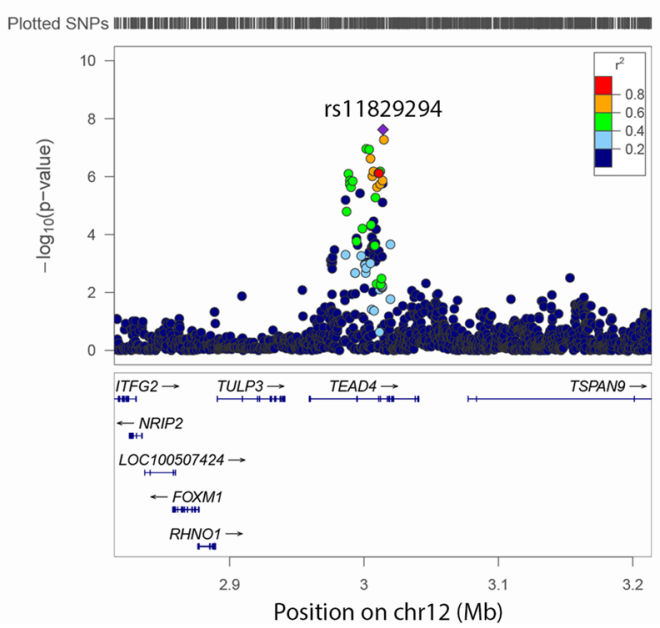

African
Plotted SNPS I

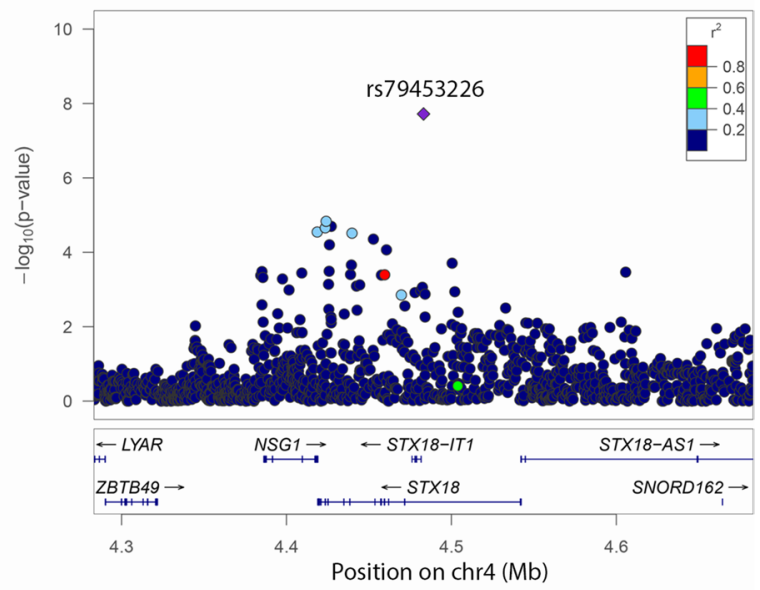

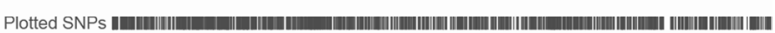

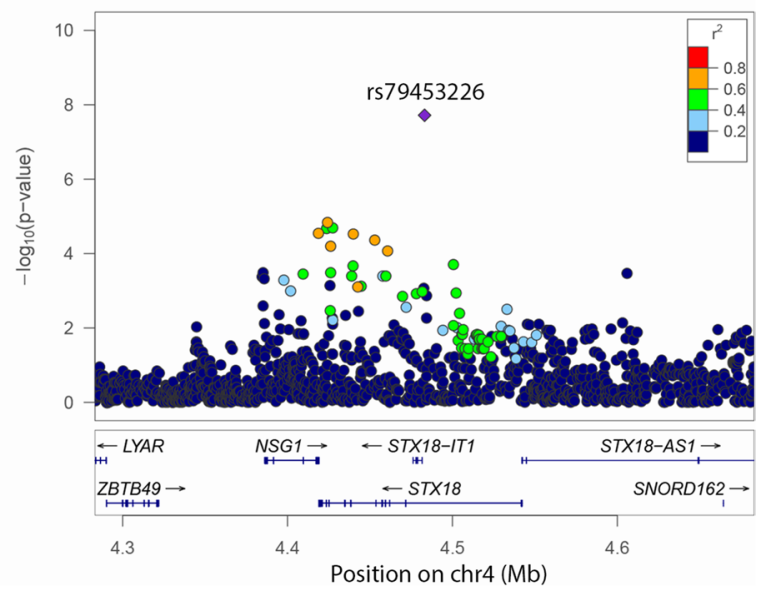

Fig. 3 Locus zoom plots for the two genome-wide significant loci. Colors represent linkage disequilibrium $r^{2}$ values calculated from TOPMed individuals with the lead SNP in each plot. a Locus zoom plots with linkage disequilibrium $r^{2}$ values calculated from TOPMed European ancestry individuals. b Locus zoom plots with linkage disequilibrium $r^{2}$ values calculated from TOPMed African ancestry individuals. NCBI build 38

Table 3 Epigenetic functional annotations for selected genome-wide significant and suggestive associations

\begin{tabular}{lllllll}
\hline rsID & P value & CADD phred & FathmmMKL & Genehancer feature & $\begin{array}{l}\text { Genehancer } \\
\text { connected gene }\end{array}$ & Locus \\
\hline rs11829294 & $2.40 \mathrm{e}-08$ & 3.728 & 0.21 & enhancer & TSPAN9 & TEAD4 (intron) \\
rs10774094 & $5.21 \mathrm{e}-08$ & 0.805 & 0.10 & enhancer & TSPAN9 & TEAD4 (intron) \\
rs16913588 & $2.05 \mathrm{e}-07$ & 7.525 & 0.97 & - & - & intergenic \\
rs58545250 & $2.14 \mathrm{e}-07$ & 9.661 & 0.49 & - & TSPAN9 & TEAD4 (intron) \\
rs61114884 & $2.39 \mathrm{e}-07$ & 3.602 & 0.15 & enhancer & - & LRIG2 (intron) \\
rs17031018 & $5.27 \mathrm{e}-07$ & 9.16 & 0.30 & - & ITPR1 & SUMF1 (intron) \\
rs79946490 & $6.64 \mathrm{e}-07$ & 10.19 & 0.23 & enhancer & TSPAN9 & TEAD4 (intron) \\
rs11062457 & $7.44 \mathrm{e}-07$ & 0.362 & 0.13 & enhancer & TSPAN9 & TEAD4 (intron) \\
rs2286647 & $7.46 \mathrm{e}-07$ & 0.16 & 0.07 & enhancer & TSPAN9 & TEAD4 (intron) \\
rs143923810 & $7.73 \mathrm{e}-07$ & 1.518 & 0.04 & enhancer & CLIC4 & NIPAL3 (downstream) \\
rs9424366 & $9.86 \mathrm{e}-07$ & 13.82 & 0.13 & enhancer & &
\end{tabular}


been implicated in signal transduction, RNA processing, transcriptional regulation, and DNA repair [72]. PRMT8 was found to be associated with the plasma membrane and has a tissue-specific expression in brain. Specifically, it is highly expressed in nucleus accumbens (basal ganglia), putamen (basal ganglia), cortex, caudate (basal ganglia), frontal cortex (Brodmann area 9), and anterior cingulate cortex (Brodmann area 24) [71]. It was also identified as a tissue-restricted enzyme responsible for proper asymmetric dimethylarginine (ADMA) level in postmitotic neurons where PRMT8dependent arginine methylation is required for neuroprotection against age-related increased of cellular stress [73]. Moreover, PRMT8 in human embryonic stem cells (hESCs) plays an important role not only in maintaining pluripotency but also in controlling mesodermal differentiation [74]. Along with the evidence that variant rs 12322215 is linked to the promoter region of $P R M T 8$, we conclude that $P R M T 8$ is another biologically plausible gene regulated by $\mathrm{eQTL}$ at the TEAD4 locus that could have potential effects on cognitive impairment among preterm children.

Additionally, we found that multiple variants in LD with rs11829294 overlapped with selective sweeps detected by S/HIC (Table 5). There is evidence that soft sweeps are widespread and account for the vast majority of recent human adaptation, and positive selection may often proceed via "soft sweeps" acting on mutations already present within a population. Furthermore, linked positive selection affects patterns of variation across much of the genome, and may increase the frequencies of deleterious mutations [69]. Therefore, these variants in soft sweep regions provide additional evidence for the associations found at the TEAD4 locus being biologically plausible and potentially causal.

For rs79453226, we found that it is linked to promoter regions of STX18 and NSG1 (Fig. 4). We did not find as much evidence for the STX18 locus supporting the significant association as for the TEAD4 locus. By examining LD $r^{2}$ values calculated from TOPMed, we observed that rs11829294 and rs79453226 have different LD structures at their loci (Fig. 3). Specifically, rs11829294 has a number of LD buddies with $r^{2} \geq 0.8$ showing suggestive association with LPAx in the European population.
In contrast, rs79453226 has fewer LD buddies and is not in high LD with any of the suggestive variants. Therefore, rs11829294 is more likely to tag effects from causal variants than rs79453226.

With association results and other information considered, we did not have direct evidence indicating TEAD4 and STX18 as causal genes. However, there is evidence that TEAD4 and STX18 are related to placental development and brain respectively.TEAD4 is a member of the TEAD transcription factor family, which is best known for transcriptional output of the Hippo signaling pathway and has been implicated in processes such as development, cell growth and proliferation, tissue homeostasis, and regeneration [75]. TEADs have been found to be evolutionarily conserved, and have been shown to play important roles in various biological processes and human disease [76, 77]. Mouse knockout studies showed that TEAD4 is specifically required for embryo implantation and trophectoderm lineage determination $[78,79]$, which play important roles in placental development. TEAD4 null mice are embryonic lethal due to failure in embryo implantation; however, disruption of TEAD4 after embryo implantation results in normal development $[78,79]$. TEADs seem to have important biological functions, but studies thoroughly characterizing TEAD function and regulation are lacking. In the future, we can utilize genome-wide DNA methylation, mRNA, and miRNA data from the placenta to study this gene more closely. The gene STX18 encodes a member of the syntaxin family of soluble $\mathrm{N}$-ethylmaleimide-sensitive factor attachment protein receptors (SNAREs) which is part of a membrane tethering complex that includes other SNAREs and several peripheral membrane proteins, and is involved in vesicular transport between the endoplasmic reticulum (ER) and the Golgi complex [80]. It has also been shown that STX18 is important for the organization of two ER subdomains, smooth/rough ER membranes and ER exit sites by mediating the fusion of retrograde membrane carriers with the ER membrane [81]. Knockdown of STX18 caused a global change in ER membrane architecture, leading to the segregation of the smooth and rough ER. Moreover, the organization of ER exit sites was markedly changed concomitantly with dispersion of

\footnotetext{
(See figure on next page.)

Fig. 4 Virtual 4C plots. Centered at a rs79453226 b rs 12322215 in adult cortex and fetal cortex. The bin containing the anchor position is indicated as a thick grey vertical bar. Different genes or regions can be highlighted in yellow. On the top is gene expression data with gene locations. Each gene is indicated by an arrow pointing the direction of transcription. The start site is indicated by the tail of the arrow. Each gene is labeled by its common name and highlighted in red indicating the expression level: the deeper the red color the higher the expression. On the bottom is the chromatin interaction $\mathrm{Hi}-\mathrm{C}$ data that is plotted as a virtual $4 \mathrm{C}$ plot with the given anchor position. The black line shows the observed counts, the red line shows the expected counts, and the blue line shows the - $\log 10$ ( $p$ value). The range of the - $\log 10$ ( $p$ value) is plotted on the $y$-axis on the right while the range of the count data is shown on the left. The $x$-axis is the genomic location in Mb. NCBI build 37
} 


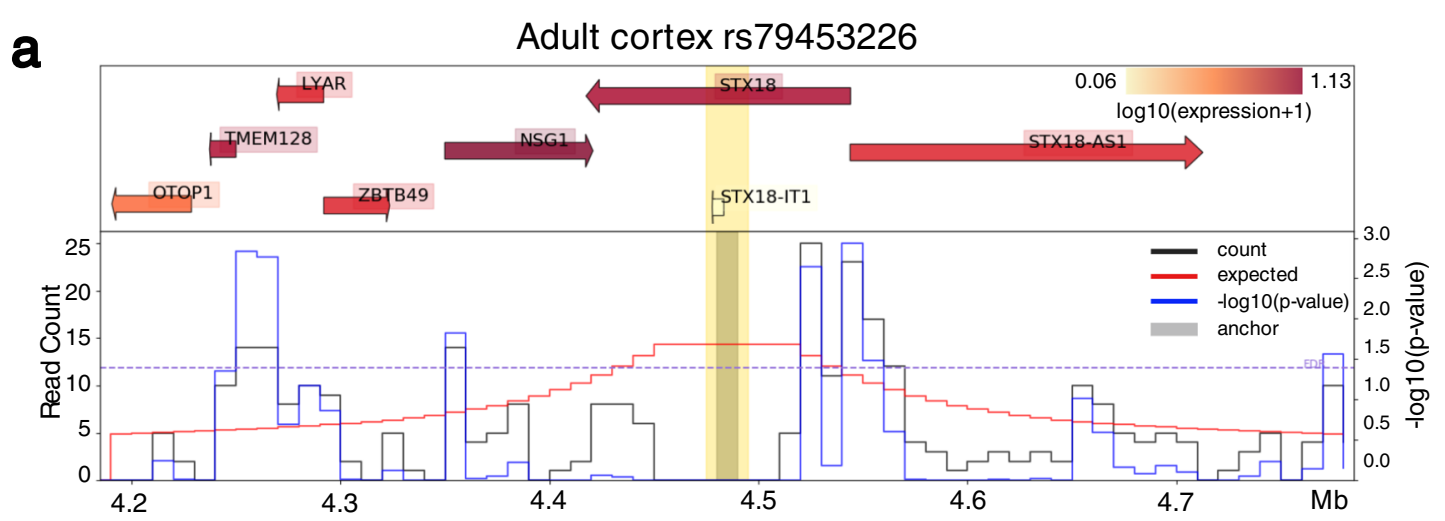

Fetal cortex rs79453226

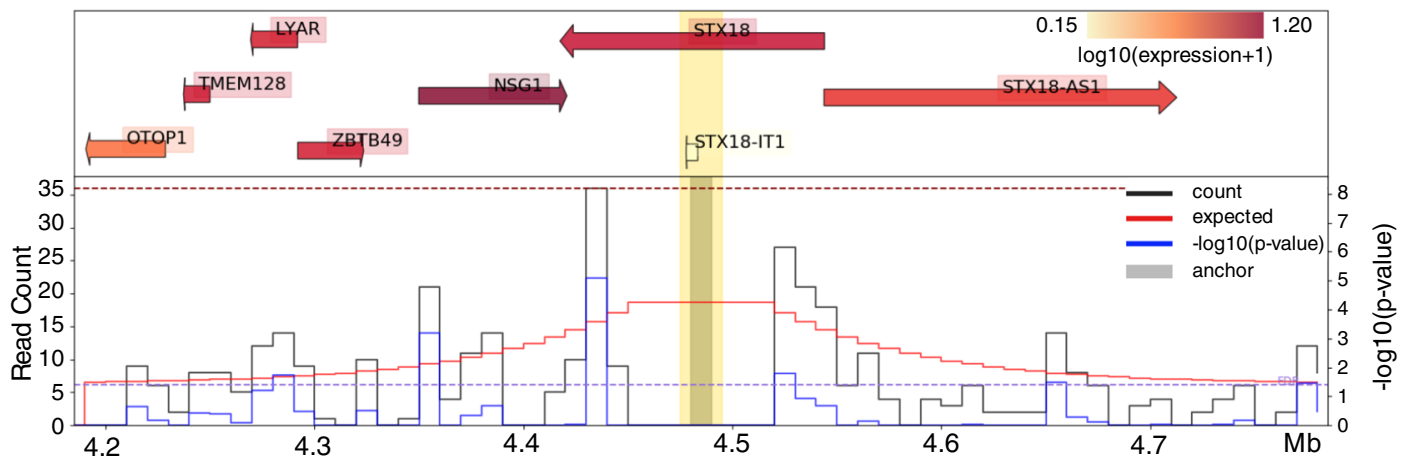

b

Adult cortex rs12322215

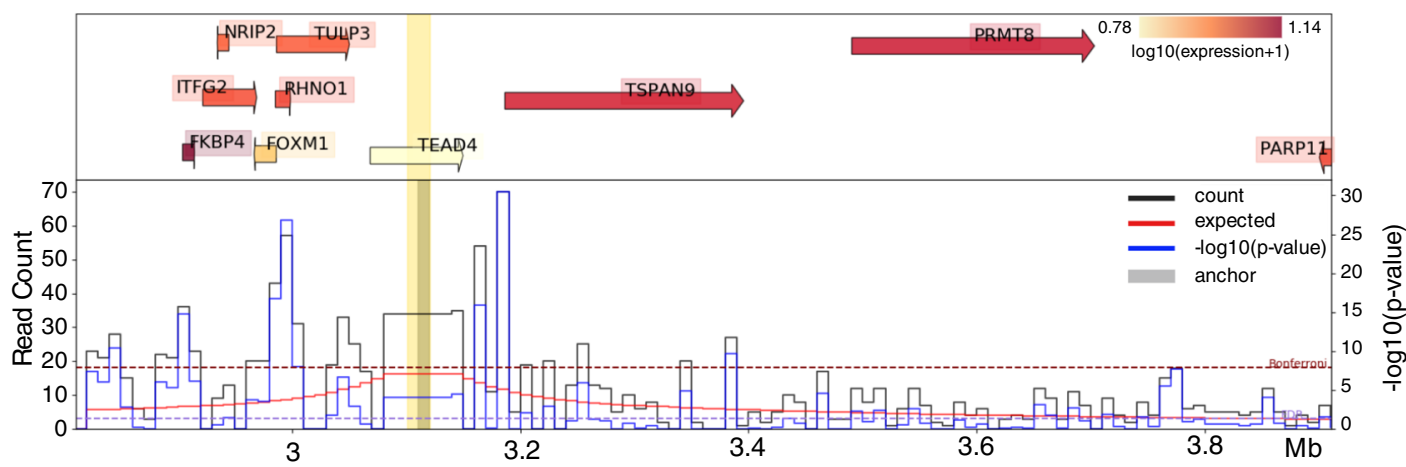

Fetal cortex rs 12322215

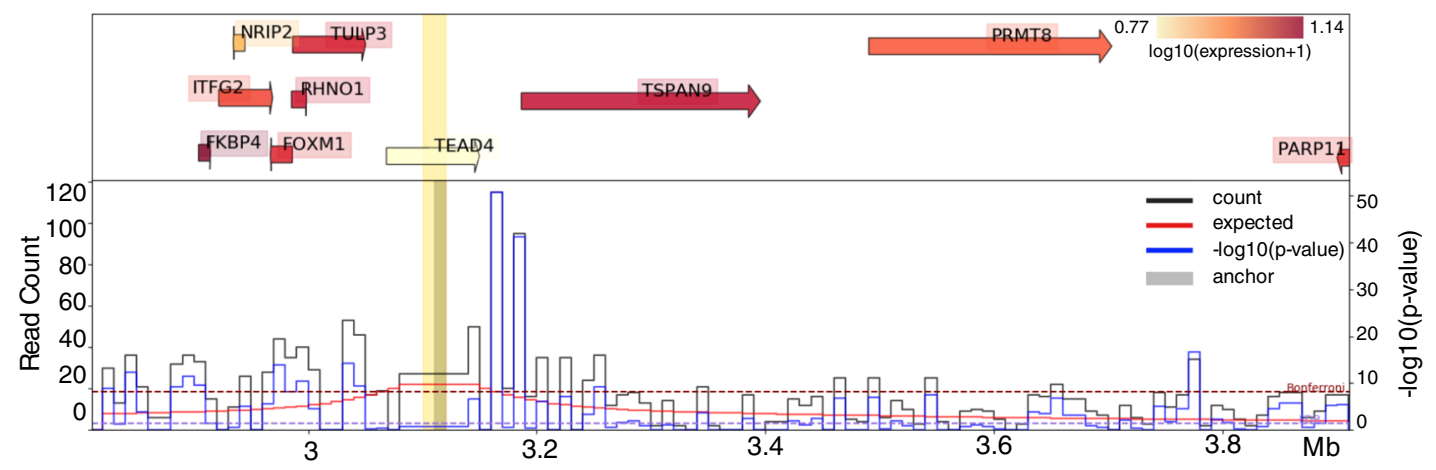

Fig. 4 (See legend on previous page.) 
Table 4 Variants overlapped with commonMind eQTL

\begin{tabular}{lllllll}
\hline rsID & Gene & Chr ${ }^{\text {a }}$ & Position & FDR & $\begin{array}{c}\text { Index SNP } \\
\text { LD r with } \\
\text { the index } \\
\text { SNP }\end{array}$ \\
\hline rs143923810 & PRMT8 & chr12 & 2988024 & 0.010 & rs11829294 & 0.724 \\
rs7302783 & PRMT8 & chr12 & 2989245 & 0.010 & rs11829294 & 0.724 \\
rs7302789 & PRMT8 & chr12 & 2989254 & 0.010 & rs11829294 & 0.720 \\
rs10082968 & PRMT8 & chr12 & 2990125 & 0.025 & rs11829294 & 0.720 \\
rs12322215 & PRMT8 & chr12 & 3001421 & 0.048 & rs11829294 & 0.883 \\
rs10128796 & PRMT8 & chr12 & 3003552 & 0.045 & rs11829294 & 0.883 \\
\hline
\end{tabular}

${ }^{\mathrm{a}} \mathrm{NCBI}$ build 38

Table 5 Variants overlapped with selective sweeps

\begin{tabular}{lllll}
\hline Chr $^{\text {a }}$ & Position $^{\text {a }}$ & Start & End & Selective sweeps \\
\hline chr12 & 3095812 & 2800000 & 3100000 & CEU: soft, GWD: soft, LWK: soft, PEL: soft, YRl: soft \\
chr12 & 3097190 & 2800000 & 3100000 & CEU: soft, GWD: soft, LWK: soft, PEL: soft, YRl: soft \\
chr12 & 3098411 & 2800000 & 3100000 & CEU: soft, GWD: soft, LWK: soft, PEL: soft, YRl: soft \\
chr12 & 3098420 & 2800000 & 3100000 & CEU: soft, GWD: soft, LWK: soft, PEL: soft, YRl: soft \\
chr12 & 3099291 & 2800000 & 3100000 & CEU: soft, GWD: soft, LWK: soft, PEL: soft, YRl: soft \\
chr2 & 82111514 & 82100000 & 82200000 & GWD: soft, YRI: soft \\
\hline
\end{tabular}

Population: CEU (UT, USA), GWD (Western Divisions, the Gambia), LWK (Webuye, Kenya), PEL (Lima, Peru), YRI (Ibadan, Nigeria). Start and end are start and end positions of selective sweep regions

${ }^{\text {a }} \mathrm{NCBI}$ build 37

the ER-Golgi intermediate compartment and the Golgi complex. Variants in STX18 were previously found to be associated with brain volume measurement and neuroimaging measurement $[82,83]$.

One limitation of our analysis is that our results may not be generalizable to children who are not extreme premature. Another issue is the small sample size, although we were able to impute most variants well (Fig. S1, Additional file), it limits the statistical power of the association analysis. The few genome-wide significant single variant associations we found, and the non-statistically significant heritability estimate also suggest the need for better powered analyses (Additional file 1). It is also possible that variants included in our analyses are in low or moderate LD with true causal variants which are rare and cannot be well-imputed in the ELGAN2 cohort. While ELGAN2 is the largest cohort with genotype and long-term cognitive assessment for extremely preterm children currently available in the USA, in the future we hope to study a larger population with longitudinal data of cognitive function, to investigate whether there are genetic variants that interact with perinatal and neonatal immune factors to increase risk for development of trajectories of impaired cognitive function.

\section{Conclusions}

In this work, we present an innovative computational approach that combines LPA with multi-faceted genomic analysis to investigate potential genetic risk factors underlying cognitive impairment among children born extremely preterm. Our association analysis identified two genome-wide significant loci: TEAD4 at rs11829294 and STX18 at rs79453226. Further genomic analysis suggests that rs11829294 and its LD buddies have potential regulatory roles on likely functionally relevant genes TSPAN9 and PMRT8. This study provides new mechanistic insight into neurocognitive function among children born extremely preterm by performing an imputationbased GWAS with subsequent prioritization of causal variants and effector genes.

\footnotetext{
Abbreviations

LPA: Latent profile analysis; GWAS: Genome-wide association study; eQTL: Expression quantitative trait loci; RCT: Randomized controlled trial; ELGAN: Extremely low gestational age newborns; IQ: Intelligence quotient; EF: Executive functioning; DAS-II: Differential Ability Scales-II; NEPSY-II: NEuroPSYchological Assessment-II; BIC: Bayesian information criteria; SSABIC: Samplesize-adjusted Bayesian information criteria; LMR: Lo-Mendell-Rubin; IVH: Intraventricular hemorrhage; QC: Quality control; MAF: Minor allele frequency; PCs: Principal components; GRM: Genetic relationship matrix; REML: Restricted maximum likelihood; Q-Q: Quantile-quantile; LD: Linkage disequilibrium; FIREs: Frequently interacting regions; ADMA: Asymmetric dimethylarginine;
} 
hESCs: Human embryonic stem cells; SNAREs: Soluble N-ethylmaleimidesensitive factor attachment protein receptors; ER: Endoplasmic reticulum.

\section{Supplementary Information}

The online version contains supplementary material available at https://doi. org/10.1186/s11689-022-09429-x.

Additional file 1. SNP-heritability estimation with GCTA, Fig. S1, and Fig. S2.

\section{Acknowledgements}

The authors gratefully acknowledge the contributions of ELGAN participants and their families, as well as those of our colleagues. We thank Dr. Timothy C. Heeren for his expertise on the LPA analysis.

\section{Authors' contributions}

Conceptualization: YL, TMO, RCF, HPS; data analysis: WL, LH, QS, GW, YL, HPS; data curation: $W L, A B, T M O, R C F, Y L, H P S$; funding acquisition: $K C K K, R M J, T M O$, $R C F, Y L, H P S$; methodology: WL, XT, YL, HPS; writing —original draft: WL, YL, HPS; writing — review and editing: WL, LH, QS, AB, GW, XT, KCKK, RMJ, TMO, $\mathrm{RCF}, \mathrm{YL}, \mathrm{HPS}$. All authors have read and approved the final manuscript and acknowledged the statement.

\section{Funding}

This work was supported by the National Institutes of Health $(\mathrm{NIH})$, including awards funded by the National Institute of Child Health and Human Development under grant\# 5R01HD092374-05, the National Institute of Nursing Research under grant\# 5R01NR019245-02, and the Office of the NIH Director grants\# P50HD103573, U01DA052713, and UH3OD023348.

\section{Availability of data and materials}

The genotype data analyzed during the current study are not publicly available but are available from the corresponding author on reasonable request. Epigenetic functional annotations, chromatin interaction, brain eQTL, and selective sweeps data are publicly available.

\section{Declarations}

\section{Ethics approval and consent to participate}

Participating mothers provided informed consent following admission to the hospital, before birth, or immediately following birth. Study procedures were approved by the Institutional Review Board at each of the 14 participating ELGAN sites.

\section{Consent for publication}

Consent for publication was granted during in informed consent process.

\section{Competing interests}

The authors declare no competing interests.

\footnotetext{
Author details

'Department of Biostatistics, University of North Carolina at Chapel Hill, Chapel Hill, NC, USA. ${ }^{2}$ Curriculum in Bioinformatics and Computational Biology, University of North Carolina at Chapel Hill, Chapel Hill, NC, USA. ${ }^{3}$ Department of Pathology and Laboratory Medicine, David Geffen School of Medicine, University of California, Los Angeles, CA, USA. ${ }^{4}$ Lineberger Comprehensive Cancer Center, University of North Carolina at Chapel Hill, Chapel Hill, NC, USA. ${ }^{5}$ Department of Pediatrics, Boston University, Boston, MA, USA. ${ }^{6}$ Department of Anatomy \& Neurobiology, Boston University, Boston, MA, USA. ${ }^{7}$ Department of Pediatrics, University of North Carolina at Chapel Hill, Chapel Hill, NC, USA. ${ }^{8}$ Department of Environmental Sciences and Engineering, University of North Carolina at Chapel Hill, Chapel Hill, NC, USA. ${ }^{9}$ Department of Genetics, University of North Carolina at Chapel Hill, Chapel Hill, NC, USA. ${ }^{10}$ Department of Computer Science, University of North Carolina at Chapel Hill, Chapel Hill, NC, USA. ${ }^{11}$ School of Nursing, University of North Carolina at Chapel Hill, Chapel Hill, NC, USA.
}

Received: 1 October 2021 Accepted: 22 February 2022

Published online: 03 March 2022

\section{References}

1. Mathews TJ, Driscoll AK. Trends in Infant Mortality in the United States, 2005-2014. NCHS Data Brief; 2017. p. 1-8.

2. Korologou-Linden R, Anderson EL, Jones HJ, Davey Smith G, Howe LD, Stergiakouli E. Polygenic risk scores for Alzheimer's disease, and academic achievement, cognitive and behavioural measures in children from the general population. Int J Epidemiol. 2019;48:1972-80.

3. Ding S, Lemyre B, Daboval T, Barrowman N, Moore GP. A meta-analysis of neurodevelopmental outcomes at 4-10 years in children born at 22-25 weeks gestation. Acta Paediatr. 2019;108:1237-44.

4. Serenius F, Källén K, Blennow M, Ewald U, Fellman V, Holmström G, et al Neurodevelopmental outcome in extremely preterm infants at 2.5 years after active perinatal care in Sweden. JAMA. 2013;309:1810-20.

5. Moore T, Hennessy EM, Myles J, Johnson SJ, Draper ES, Costeloe KL, et al. Neurological and developmental outcome in extremely preterm children born in England in 1995 and 2006: the EPICure studies. BMJ. 2012;345:e7961.

6. Pascal A, Govaert P, Oostra A, Naulaers G, Ortibus E, Van den Broeck C. Neurodevelopmental outcome in very preterm and very-low-birthweight infants born over the past decade: a meta-analytic review. Dev Med Child Neurol. 2018;60:342-55.

7. Joseph RM, O'Shea TM, Allred EN, Heeren T, Hirtz D, Jara H, et al. Neurocognitive and academic outcomes at age 10 years of extremely preterm newborns. Pediatrics. 2016;137(4). https://doi.org/10.1542/ peds.2015-4343.

8. Kuban KCK, Joseph RM, O'Shea TM, Allred EN, Heeren T, Douglass L, et al. Girls and boys born before 28 weeks gestation: risks of cognitive, behavioral, and neurologic outcomes at age 10 years. J Pediatr. 2016;173:69-75.e1.

9. Johnson S, Fawke J, Hennessy E, Rowell V, Thomas S, Wolke D, et al. Neurodevelopmental disability through 11 years of age in children born before 26 weeks of gestation. Pediatrics. 2009;124(2):e249-57. https://doi.org/10.1542/peds.2008-3743.

10. Russ SA, Larson K, Halfon N. A national profile of childhood epilepsy and seizure disorder. Pediatrics. 2012;129(2):256-64. https://doi.org/10. 1542/peds.2010-1371.

11. Johnson S, Marlow N. Early and long-term outcome of infants born extremely preterm. Arch Dis Child. 2017;102:97-102.

12. Chan E, Leong P, Malouf R, Quigley MA. Long-term cognitive and school outcomes of late-preterm and early-term births: a systematic review. Child Care Health Dev. 2016:42:297-312.

13. Van Naarden BK, Christensen D, Doernberg N, Schieve L, Rice C, Wiggins $L$, et al. Trends in the prevalence of autism spectrum disorder, cerebral palsy, hearing loss, intellectual disability, and vision impairment, metropolitan atlanta, 1991-2010. PLoS One. 2015;10:e0124120.

14. Blencowe H, Lee ACC, Cousens S, Bahalim A, Narwal R, Zhong N, et al. Preterm birth-associated neurodevelopmental impairment estimates at regional and global levels for 2010. Pediatr Res. 2013;74(Suppl 1):17-34.

15. Crowley P. Prophylactic corticosteroids for preterm birth. Cochrane Database Syst Rev. 2000;(2):CD000065. https://doi.org/10.1002/14651 858.CD000065.

16. Schmidt B, Anderson PJ, Doyle LW, Dewey D, Grunau RE, Asztalos EV, et al. Survival without disability to age 5 years after neonatal caffeine therapy for apnea of prematurity. JAMA. 2012;307:275-82.

17. Schmidt B, Davis P, Moddemann D, Ohlsson A, Roberts RS, Saigal S, et al. Long-term effects of indomethacin prophylaxis in extremely-lowbirth-weight infants. N Engl J Med. 2001;344:1966-72.

18. Brooks-Gunn J, McCarton CM, Casey PH, McCormick MC, Bauer CR, Bernbaum JC, et al. Early intervention in low-birth-weight premature infants. Results through age 5 years from the Infant Health and Development Program. JAMA. 1994;272:1257-62.

19. Maxwell JR, Yellowhair TR, Oppong AY, Camacho JE, Lowe JR, Jantzie $L L$, et al. Cognitive development in preterm infants: multifaceted deficits reflect vulnerability of rigorous neurodevelopmental pathways. Minerva Pediatr. 2017;69:298-313. 
20. Murray AL, Scratch SE, Thompson DK, Inder TE, Doyle LW, Anderson JFI, et al. Neonatal brain pathology predicts adverse attention and processing speed outcomes in very preterm and/or very low birth weight children. Neuropsychology. 2014;28:552-62.

21. Twilhaar ES, Wade RM, de Kieviet JF, van Goudoever JB, van Elburg RM, Oosterlaan J. Cognitive outcomes of children born extremely or very preterm since the 1990s and associated risk factors: a meta-analysis and meta-regression. JAMA Pediatr. 2018;172:361-7.

22. Buescher AVS, Cidav Z, Knapp M, Mandell DS. Costs of autism spectrum disorders in the United Kingdom and the United States. JAMA Pediatr. 2014;168:721-8.

23. Centers for Disease Control and Prevention (CDC). Economic costs associated with mental retardation, cerebral palsy, hearing loss, and vision impairment_United States, 2003. MMWR Morb Mortal Wkly Rep. 2004;53:57-9.

24. Grove J, Ripke S, Als TD, Mattheisen M, Walters RK, Won H, et al. Identification of common genetic risk variants for autism spectrum disorder. Nat Genet. 2019;51:431-44.

25. Demontis D, Walters RK, Martin J, Mattheisen M, Als TD, Agerbo E, et al. Discovery of the first genome-wide significant risk loci for attention deficit/hyperactivity disorder. Nat Genet. 2019;51:63-75.

26. Tatton-Brown K, Loveday C, Yost S, Clarke M, Ramsay E, Zachariou A, et al. Mutations in epigenetic regulation genes are a major cause of overgrowth with intellectual disability. Am J Hum Genet. 2017;100:725-36.

27. Stessman HAF, Willemsen MH, Fenckova M, Penn O, Hoischen A, Xiong $B$, et al. Disruption of POGZ is associated with intellectual disability and autism spectrum disorders. Am J Hum Genet. 2016;98:541-52.

28. Andres EM, Hafeez H, Yousaf A, Riazuddin S, Rice ML, Basra MAR, et al. A genome-wide analysis in consanguineous families reveals new chromosomal loci in specific language impairment (SLI). Eur J Hum Genet. 2019;27:1274-85.

29. Mehta CM, Gruen JR, Zhang H. A method for integrating neuroimaging into genetic models of learning performance. Genet Epidemiol. 2017:41:4-17.

30. Ambalavanan A, Girard SL, Ahn K, Zhou S, Dionne-Laporte A, Spiegelman $\mathrm{D}$, et al. De novo variants in sporadic cases of childhood onset schizophrenia. Eur J Hum Genet. 2016;24:944-8.

31. Yao N-J, Hsieh W-S, Lin C-H, Tseng C-I, Lin W-Y, Kuo P-H, et al. Interaction between prematurity and the MAOA gene on mental development in children: a longitudinal view. Front Pediatr. 2020;8:92.

32. Dutt A, Shaikh M, Ganguly T, Nosarti C, Walshe M, Arranz M, et al. COMT gene polymorphism and corpus callosum morphometry in preterm born adults. Neuroimage. 2011;54:148-53.

33. Costantine MM, Clark EAS, Lai Y, Rouse DJ, Spong CY, Mercer BM, et al. Association of polymorphisms in neuroprotection and oxidative stress genes and neurodevelopmental outcomes after preterm birth. Obstet Gynecol. 2012;120:542-50.

34. Clark EAS, Mele L, Wapner RJ, Spong CY, Sorokin Y, Peaceman A, et al. Association of fetal inflammation and coagulation pathway gene polymorphisms with neurodevelopmental delay at age 2 years. Am J Obstet Gynecol. 2010;203:83.e1-83.e10.

35. Blair LM, Pickler RH, Anderson C. Integrative review of genetic factors influencing neurodevelopmental outcomes in preterm infants. Biol Res Nurs. 2016;18:127-37.

36. Blair LM, Pickler RH, Gugiu PC, Ford JL, Munro CL, Anderson CM. Genetic risk factors for poor cognitive development in children with low birth weight. Biol Res Nurs. 2020;22:5-12.

37. O'Shea TM, Allred EN, Dammann O, Hirtz D, Kuban KCK, Paneth N, et al. The ELGAN study of the brain and related disorders in extremely low gestational age newborns. Early Hum Dev. 2009;85:719-25.

38. Heeren T, Joseph RM, Allred EN, O'Shea TM, Leviton A, Kuban KCK. Cognitive functioning at the age of 10 years among children born extremely preterm: a latent profile approach. Pediatr Res. 2017;82:614-9.

39. Kongsted A, Nielsen AM. Latent class analysis in health research. J Physiother. 2017;63:55-8.

40. Schwarz G. Estimating the Dimension of a Model. Ann Statist. 1978;6:461-4.

41. Sclove SL. Application of model-selection criteria to some problems in multivariate analysis. Psychometrika. 1987;52:333-43.
42. Lo Y, Mendell NR, Rubin DB. Testing the number of components in a normal mixture. Biometrika. 2001;88:767-78.

43. Meakin CJ, Martin EM, Santos HP, Mokrova I, Kuban K, O'Shea TM, et al. Placental $\mathrm{CpG}$ methylation of HPA-axis genes is associated with cognitive impairment at age 10 among children born extremely preterm. Horm Behav. 2018;101:29-35.

44. Adén U, Lin A, Carlo W, Leviton A, Murray JC, Hallman M, et al. Candidate gene analysis: severe intraventricular hemorrhage in inborn preterm neonates. J Pediatr. 2013;163:1503-6.e1.

45. Chang CC, Chow CC. PLINK 1.9 [Internet]. [cited 2021 Jan 15]. Available from: http://www.cog-genomics.org/plink/1.9/

46. Chang CC, Chow CC, Tellier LC, Vattikuti S, Purcell SM, Lee JJ. Secondgeneration PLINK: rising to the challenge of larger and richer datasets. Gigascience. 2015;4:7.

47. Das S, Forer L, Schönherr S, Sidore C, Locke AE, Kwong A, et al. Nextgeneration genotype imputation service and methods. Nat Genet. 2016:48:1284-7.

48. TOPMed Whole Genome Sequencing Project - Freeze 5b, Phases 1 and 2 [Internet]. 2020 [cited 2021 Jan 15]. Available from: https:// www.nhlbiwgs.org/topmed-whole-genome-sequencing-proje ct-freeze-5b-phases-1-and-2

49. Loh P-R, Danecek P, Palamara PF, Fuchsberger C, Reshef YA, Finucane HK, et al. Reference-based phasing using the Haplotype Reference Consortium panel. Nat Genet. 2016;48:1443-8.

50. Fuchsberger C, Abecasis GR, Hinds DA. minimac2: faster genotype imputation. Bioinformatics. 2015;31:782-4.

51. statgen/Minimac4 [Internet]. [cited 2021 Jan 15]. Available from: https:// github.com/statgen/Minimac4

52. Li Y, Willer CJ, Ding J, Scheet P, Abecasis GR. MaCH: using sequence and genotype data to estimate haplotypes and unobserved genotypes. Genet Epidemiol. 2010;34:816-34.

53. Duan Q, Liu EY, Croteau-Chonka DC, Mohlke KL, Li Y. A comprehensive SNP and indel imputability database. Bioinformatics. 2013;29:528-31.

54. Kowalski MH, Qian H, Hou Z, Rosen JD, Tapia AL, Shan Y, et al. Use of $>100,000$ NHLBI Trans-Omics for Precision Medicine (TOPMed) Consortium whole genome sequences improves imputation quality and detection of rare variant associations in admixed African and Hispanic/Latino populations. PLoS Genet. 2019;15:e1008500.

55. EPACTS - Genome Analysis Wiki [Internet]. [cited 2021 Jan 15]. Available from: https://genome.sph.umich.edu/wiki/EPACTS

56. Kang HM, Sul JH, Service SK, Zaitlen NA, Kong S-Y, Freimer NB, et al. Variance component model to account for sample structure in genomewide association studies. Nat Genet. 2010;42:348-54.

57. Gel B, Serra E. karyoploteR: an R/Bioconductor package to plot customizable genomes displaying arbitrary data. Bioinformatics. 2017:33:3088-90.

58. Turner $\mathrm{S}$. qqman: an $\mathrm{R}$ package for visualizing GWAS results using Q-Q and manhattan plots. JOSS. 2018:3:731.

59. Pruim RJ, Welch RP, Sanna S, Teslovich TM, Chines PS, Gliedt TP, et al. LocusZoom: regional visualization of genome-wide association scan results. Bioinformatics. 2010;26:2336-7.

60. TopLD [Internet]. [cited 2021 Apr 13]. Available from: http://topld.genet ics.unc.edu/topld/

61. Rentzsch P, Witten D, Cooper GM, Shendure J, Kircher M. CADD: predicting the deleteriousness of variants throughout the human genome. Nucleic Acids Res. 2019;47:D886-94.

62. Shihab HA, Rogers MF, Gough J, Mort M, Cooper DN, Day INM, et al. An integrative approach to predicting the functional effects of non-coding and coding sequence variation. Bioinformatics. 2015;31:1536-43.

63. Fishilevich S, Nudel R, Rappaport N, Hadar R, Plaschkes I, Iny Stein T, et al. GeneHancer: genome-wide integration of enhancers and target genes in GeneCards. Database (Oxford). 2017;2017. https://doi.org/10.1093/datab ase/bax028.

64. Hugin2 [Internet]. [cited 2021 Jan 16]. Available from: http://hugin2.genet ics.unc.edu/Project/hugin/

65. Giusti-Rodriguez P, Lu L, Yang Y, Crowley CA, Liu X, Juric I, et al. Using three-dimensional regulatory chromatin interactions from adult and fetal cortex to interpret genetic results for psychiatric disorders and cognitive traits. BioRxiv. 2018. https://doi.org/10.1101/406330. 
66. Fudenberg G, Imakaev M, Lu C, Goloborodko A, Abdennur N, Mirny LA. Formation of chromosomal domains by loop extrusion. Cell Rep. 2016;15:2038-49.

67. Crowley C, Yang Y, Qiu Y, Hu B, Abnousi A, Lipiński J, et al. FIREcaller: Detecting frequently interacting regions from $\mathrm{Hi}-\mathrm{C}$ data. Comput Struct Biotechnol J. 2021;19:355-62.

68. Fromer M, Roussos P, Sieberts SK, Johnson JS, Kavanagh DH, Perumal TM, et al. Gene expression elucidates functional impact of polygenic risk for schizophrenia. Nat Neurosci. 2016:19:1442-53.

69. Schrider DR, Kern AD. Soft sweeps are the dominant mode of adaptation in the human genome. Mol Biol Evol. 2017;34:1863-77.

70. Protty MB, Watkins NA, Colombo D, Thomas SG, Heath VL, Herbert JMJ, et al. Identification of Tspan9 as a novel platelet tetraspanin and the collagen receptor $\mathrm{GPVI}$ as a component of tetraspanin microdomains. Biochem J. 2009;417:391-400.

71. GTEx Portal [Internet]. [cited 2021 Apr 14]. Available from: https://gtexp ortal.org/home/

72. Lee J, Sayegh J, Daniel J, Clarke S, Bedford MT. PRMT8, a new membranebound tissue-specific member of the protein arginine methyltransferase family. J Biol Chem. 2005;280:32890-6.

73. Simandi Z, Pajer K, Karolyi K, Sieler T, Jiang L-L, Kolostyak Z, et al. Arginine methyltransferase PRMT8 provides cellular stress tolerance in aging motoneurons. J Neurosci. 2018;38:7683-700.

74. Jeong H-C, Park S-J, Choi J-J, Go Y-H, Hong S-K, Kwon O-S, et al. PRMT8 controls the pluripotency and mesodermal fate of human embryonic stem cells by enhancing the PI3K/AKT/SOX2 axis. Stem Cells. 2017:35:2037-49.

75. Lin KC, Park HW, Guan K-L. Regulation of the hippo pathway transcription factor TEAD. Trends Biochem Sci. 2017;42:862-72.

76. Jin Y, Messmer-Blust AF, Li J. The role of transcription enhancer factors in cardiovascular biology. Trends Cardiovasc Med. 2011;21:1-5.

77. Pobbati AV, Hong W. Emerging roles of TEAD transcription factors and its coactivators in cancers. Cancer Biol Ther. 2013;14:390-8.

78. Yagi R, Kohn MJ, Karavanova I, Kaneko KJ, Vullhorst D, DePamphilis ML, et al. Transcription factor TEAD4 specifies the trophectoderm lineage at the beginning of mammalian development. Development 2007;134:3827-36.

79. Nishioka N, Yamamoto S, Kiyonari H, Sato H, Sawada A, Ota M, et al. Tead4 is required for specification of trophectoderm in pre-implantation mouse embryos. Mech Dev. 2008;125:270-83.

80. Hatsuzawa K, Hirose H, Tani K, Yamamoto A, Scheller RH, Tagaya M. Syntaxin 18, a SNAP receptor that functions in the endoplasmic reticulum, intermediate compartment, and cis-Golgi vesicle trafficking. J Biol Chem. 2000;275:13713-20.

81. linuma T, Aoki T, Arasaki K, Hirose H, Yamamoto A, Samata R, et al. Role of syntaxin 18 in the organization of endoplasmic reticulum subdomains. J Cell Sci. 2009;122:1680-90.

82. Zhao B, Luo T, Li T, LiY, Zhang J, Shan Y, et al. Genome-wide association analysis of 19,629 individuals identifies variants influencing regional brain volumes and refines their genetic co-architecture with cognitive and mental health traits. Nat Genet. 2019;51:1637-44.

83. van der Meer D, Frei O, Kaufmann T, Shadrin AA, Devor A, Smeland OB, et al. Understanding the genetic determinants of the brain with MOSTest. Nat Commun. 2020;11:3512.

\section{Publisher's Note}

Springer Nature remains neutral with regard to jurisdictional claims in published maps and institutional affiliations.

Ready to submit your research? Choose BMC and benefit from:

- fast, convenient online submission

- thorough peer review by experienced researchers in your field

- rapid publication on acceptance

- support for research data, including large and complex data types

- gold Open Access which fosters wider collaboration and increased citations

- maximum visibility for your research: over $100 \mathrm{M}$ website views per year

At BMC, research is always in progress.

Learn more biomedcentral.com/submissions 